\title{
Restrictive myopic myopathy: computed tomography, magnetic resonance imaging, echography, and histological findings
}

\author{
Süleyman Kaynak, Ismet Durak, Dinç Özaksoy, Tülay Canda
}

Restrictive ocular motility disturbances associated with high myopia (myopic myopathy) is a rarely seen phenomenon. Though the exact aetiology of myopic myopathy (MM) is not known, progressive neurogenic palsy, ${ }^{12}$ structural changes of muscles, ${ }^{3}$ paralysis, ${ }^{4}$ and myositis ${ }^{5}$ are suggested as the cause of $M M$.

A case of $M M$ with computed tomography (CT), magnetic resonance imaging (MRI), echographic findings, and histological examination of medial recti is reported.

\section{Case report}

Department of

Ophthalmology, Dokuz Eylül University School of Medicine, Izmir,

Turkey

S Kaynak

I Durak

Department of

Radiology, Dokuz Eylül

University School of

Medicine, Izmir, Turkey

D Özaksoy

Department of

Pathology, Dokuz Eylül

University School of

Medicine, Izmir, Turkey

T Canda

Correspondence to:

Dr Süleyman Kaynak,

Mithatyasa cad

Mithatpaşa cad

Izmir, Turkey.

Accepted for publication

7 December 1993

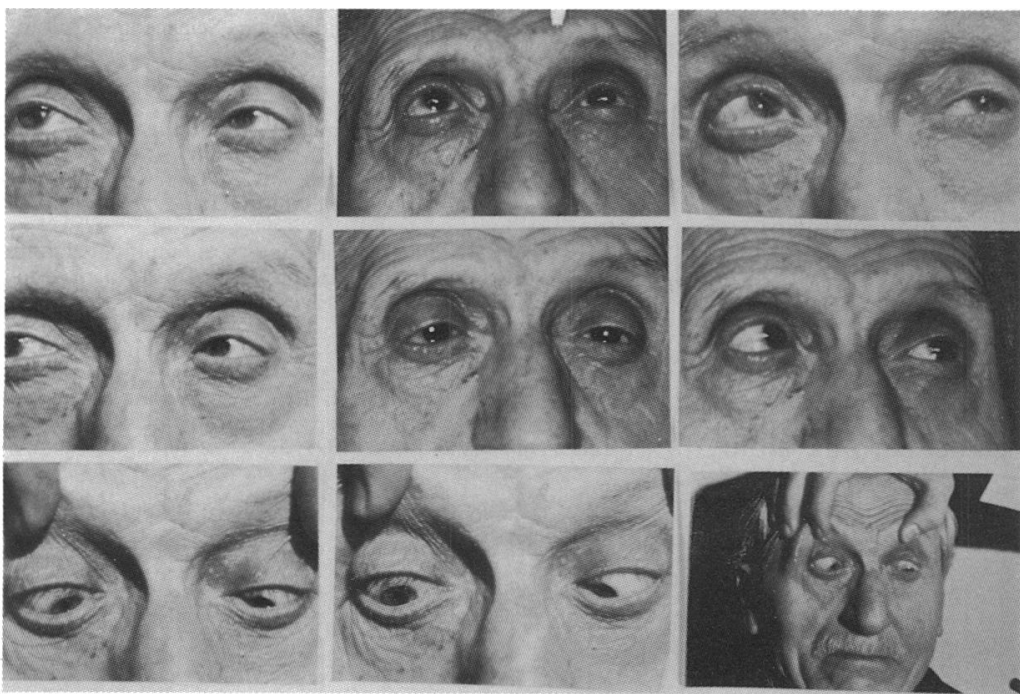

Figure 1 Positions of the eyes in three patients with myopic myopathy in all fields of gaze showing bilateral limitation of abduction, more marked in the left eye. intraocular had a history of lens extraction and the left eye and cataract in the right eye. Best corrected visual acuity was hand movements in the right eye and $1 / 10$ in the left eye.

Ophthalmoscopy showed annular conus, chorioretinal atrophy, and posterior staphyloma in the left eye. Axial lengths of the eyes were $32.7 \mathrm{~mm}$ and $33.9 \mathrm{~mm}$ in the right and left eyes respectively. The patient exhibited $30 \Delta \mathrm{D}$ esotropia with bilateral limitation of abduction more marked in the left eye (Fig 1).

Axial CT and MRI scan of the orbits showed significant elongation and enlargement of both eyes. Both lateral recti were extremely thin and there was almost no space between the eyeballs and anterior parts of lateral orbital walls (Fig 2). Examination of thyroid gland and thyroid tests were normal.

With echography, flattening of the postero-

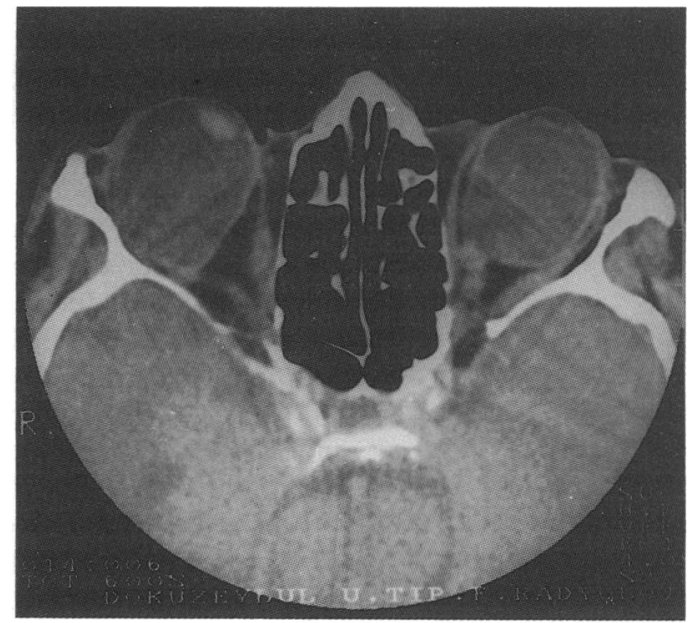

Fig $2 A$

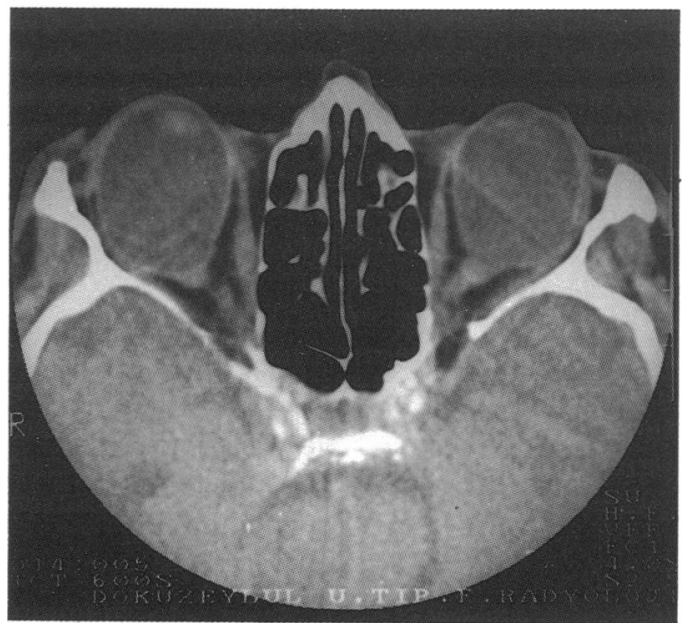

Fig $2 B$

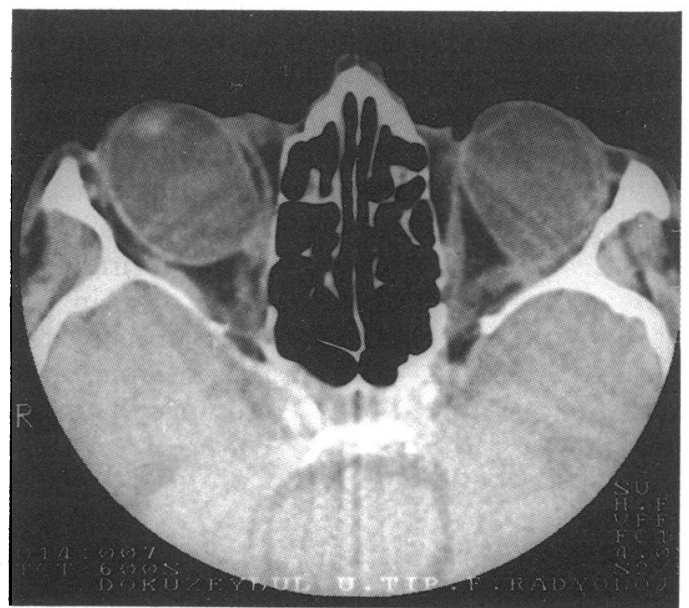

Fig $2 C$

Figure 2 Computed tomography scans of the orbits. (A) Laevoversion. (B) Primary position. (C) Dextroversion. 
lateral part of the globe and angulation was seen during adduction. Histological examination showed fibrosis and minimal atrophy of the medial rectus.

\section{Comment}

Hugonnier and Magnard ${ }^{5}$ claimed that the aetiology of MM is myositis. Our patient showed limited abduction and positive forced duction test as in Hugonnier and Magnard's cases, but in addition there was atrophy and fibrosis of medial rectus muscle fibres by histological examination. $\mathrm{Knapp}^{6}$ also reported the same ocular motility abnormalities in patients with high myopia without histological abnormalities. Zolog found disappearance of muscular fibres of lateral recti in two similar patients.

Bagolini and coworkers ${ }^{4}$ claimed that pressure of the large globe on the lateral rectus results in paralysis of the muscle with subsequent esotropia in six patients with MM. They stated that in addition to paralysis of the lateral rectus, direct pressure on the muscle or capillary bed may play an important role in the aetiology. Instead of a marked forced duction test at adduction, they found only a slightly increased cytoplasmic component of muscle fibres and moderate hypertrophy on histological examination of the medial rectus; but we found substantially increased connective tissues and diminished dimension of myofibres.

Demer and Von Noorden ${ }^{8}$ reported a high myope patient with restrictive motility disturbance owing to the contact between the elongated globe and the medial wall of the orbit. But orbital CTs and MRIs of our patient demonstrated enough space at maximum abduction between the medial rectus and the globe. Ruttum et $a l^{9}$ demonstrated flattening of the posteromedial wall of the globe against the medial orbital wall at abduction in a patient with $M M$. We have seen flattening of the posterolateral wall of the globe at adduction but not at abduction, so we do not think that the limitation of abduction is caused by contact between the globe and medial wall of the orbit.

In patients with myopia, the globe continues to enlarge during adulthood while the orbit ceases to grow. When the eye continues to grow, it begins to compress on the lateral rectus. As a result of this compression, lateral rectus becomes atrophic and esotropia occurs. Long standing esotropia may cause medial rectus fibrosis, in turn further increasing esotropia. In the later decades, atrophy of the soft orbital tissues may contribute to lateral rectus dysfunction by decreasing the protective effect of the muscle.

1 Curtin BJ. Ocular findings and complications. In: The myopias. Basic science and clinical management. Hagerstown: Harper Basic science and clinical

2 Hullo A. Les Paralysies oculomotrices et les deficits oculomoteurs. Conference Lyonnaise d'Ophtalmologie 1982; 153: 598.

3 Duke-Elder S, Wybar K. System of ophthalmology. Vol 6. Ocular motility and strabismus. London: Kimpton, 1973: 607-8.

4 Bagolini B, Tamburelli C, Dickmann A, Colosimo C. Convergent strabismus fixus in high myopic patients. Doc Ophthalmol 1990; 74: 309-20.

5 Hugonnier R, Magnard P. Les desequilibres oculemoteurs observes en cas de myopie forte. Ann Oculist 1969; 202: 71324 .

6 Knapp P. Special type of muscle anomalies associated with Graves' diseases. Ophthalmology 1979; 86: 2081-4.

7 Zolog N. Miopatia Dreptului extern in myopia forte cu esotropie excesiva. Oftalmologica 1969; 13: 315.

8 Demer JL, Von Noorden GK. High myopia as an unusual cause of restrictive ocular motility disturbance. Surv Ophthalmol 1989; 33: $281-4$.

9 Ruttum MS, Lyold MA, Lewandowski MF. Echography in the diagnosis of restrictive motility caused by severe myopia. [Letter] Am ₹ Ophthalmol 1990; 109: 350-1.

\section{Trisomy $4 \mathrm{p}$ and ocular defects}

\author{
Division of Human \\ Genetics, Department of \\ Pediatrics, University of \\ Maryland at Baltimore \\ School of Medicine, \\ Baltimore, Maryland, \\ USA \\ I W Lurie \\ Genetic Counseling \\ Center, Amur Regional \\ Hospital, \\ Blagoveshchensk, Russia \\ V A Samochvalov \\ Correspondence to: \\ Iosif W Lurie, MD, Division \\ of Human Genetics, Suite \\ 400, 405 W Redwood Street, \\ Baltimore, MD 21201-1703, \\ USA. \\ Accepted for publication \\ 1 December 1993
}

\author{
Iosif W Lurie, Vladimir A Samochvalov.
}

Trisomy of the short arm of chromosome 4 is a relatively well studied pathology. At least 85 cases have been reported, ${ }^{1-12} 74$ of them were reviewed by Kleczkowska et al..$^{9}$ Despite the fact that most patients with trisomy $4 p$ have no serious eye defects, some recent data suggest that ' some forms of ocular pathology may be relatively common for this condition.

\section{Case report}

A girl was born at term after the first pregnancy of healthy 22-year-old unrelated parents. Her birth weight was $3200 \mathrm{~g}$ and length was $52 \mathrm{~cm}$. Severe microphthalmos on the right and uveal tract coloboma on the left were mentioned in the delivery room. Further ophthalmic examination revealed coloboma of the iris, choroid, and retina. The right eye was enucleated and replaced by a prosthesis.

Examination at the age of 4 years and 4 months showed a relatively short girl $(97 \mathrm{~cm}$, just below the 5 th percentile) with normal weight $(17 \cdot 2 \mathrm{~kg}$, above 50th percentile) and head circumference. Her fine motor development and speech were delayed. She had brachycephaly, a large nose 